\title{
Scald Burn Protection of the Commercially Available Children's Sleepwear
}

\author{
AKM Mashud Alam*, Yulin Wu and Chunhui Xiang \\ Department of Apparel, Events, and Hospitality Management, Iowa State University, USA
}

*Corresponding author: AKM Mashud Alam, Department of Apparel, Events, and Hospitality Management, Iowa State University, USA.

Received Date: January 03, 2020

Published Date: January 16, 2020

\begin{abstract}
Children's sleepwear is often recalled from the consumer market due to non-conformance; however, scholarly articles auditing the thermal protection performance of commercially available children's sleepwear are scarce. Moreover, the protection against hot liquid exposure, a prevalent cause of child burn injury, has never been studied. This study examines the integrity of the commercially available children's sleepwear with Flammable Fabrics Act, and thermal protection performance against hot splash. Sleepwear knitted in different structures with different fiber compositions were selected and exposed to vertical flammability tester and hot liquid tester. A very poor splash protection was observed by all the fabrics under study. Although, all of the fabrics passed the vertical flammability test; dangerous molten polymer hazard posed by the synthetic polyester fabrics calls for a careful selection of fibers for this sophisticated class of apparel. A better protection performance could be envisioned should the fabrics were made rich of inherently flame-retardant fibers.
\end{abstract}

Keywords: Children's sleepwear; Vertical flammability; Thermal protection; Scald (splash) protection; Jersey knit; Interlock knit; Modacrylic fiber

\section{Introduction}

Children's sleepwear, as defined by the US consumer product safety commission (US CPSC), are the clothing sized above 9 months and up to size 14 that are primarily used for sleeping or sleeping related activities. US CPSC enforced children's sleepwear safety regulations in Flammable Fabrics Act. According to the act, children's sleepwear should either be snug fitted, or it must pass certain flammability test. The sleepwear standard was formulated to protect children from serious burn injury imitated from sleep ware or similar garments like pajamas, robes or nightgowns [1].

Although people from all age, gender, race, ethnicity, and socioeconomic status are susceptible to burn injury, the children are the most vulnerable class of people who suffer from burns [2]. Tragically, 24\% of all burn injuries in United States (USA) occur in children, and burn deaths were the $3^{\text {rd }}$ and $5^{\text {th }}$ among all injury deaths in children aged 5-9, and 1-4 years respectively during the period of 2011-2015 [3]. Tragically, 24\% of all burn injuries in United States (USA) occur in children, and burn deaths were the $3^{\text {rd }}$ and $5^{\text {th }}$ among all injury deaths in children aged 5-9, and 1-4 years respectively during the period of 2011-2015 [3-5]. Mcloughlin et al., in their article on sleepwear related burn injuries among children, reviewed the records of 678 burn injuries over 8 years period in a burn unit, and reported that more than $27 \%$ of sleepwear related injuries are scald injuries caused by hot liquids $[6,7]$. However, the scald protection of the children's sleepwear has never been studied before [8].

Material parameters associated with flammability of fabrics such as (i) ease of ignition (ii) heat release rate (iii) total heat release (iv) flame propagation rate and (v) mechanism of heat transfer has been studied extensively [9]. Clothing made of natural fibers such as cotton poses sudden ignition hazard as they burn readily $[10,11]$. On the other hand, synthetics such as polyester introduce molten polymer hazard owing to their thermoplasticity [10]. It has been reported that hotter burning component (such as polyester) in a blend enhances the burning rate of the cooler (such as cotton) component, and the flame temperatures be the same as hotter component $[12,13]$. The danger of polyester-cotton blends', [14]. Cotton knitted fabrics either employ inherently flameretardant fibers (such as modacrylic) in the blend to increase the limiting oxygen index (LOI) or being finished with synthetic flame retardants that can cause cancer in human body [15-17]. It is 
empirical that, fiber and fabric parameters need to be reconsidered to design a sleepwear especially for children.

Alarmingly, very often children's sleepwear including nightgowns and pajama are recalled from the market by the suppliers for non-conforming to flammability standards. Very recently in 2017, Asherangel recalled 950 pcs of cotton sleepwear, Richie House recalled 1500 children's 100\% polyester robes, Sweet Bamboo recalled 500 children's 50/50 polyester/viscose sleepwear. However, scholarly article auditing the commercially available children's sleepwear is very limited. This research, therefore, aims to audit the integrity of the commercially available children's sleepwear to the FFA, and to examine the scald protection for the first time against hot liquid splash.

Commercially available snug fitting children's sleepwear were purchased from stores and online and selected for this study based on their material properties including fiber composition, structure, and fabric weight. Their physical, durability, and comfort related properties were determined. Integrity with the FFA was evaluated by vertical flammability tester. Protection against scald injury was evaluated by using hot liquid splash tester. This result would provide insight to better understand the protection performance provided by children's sleepwear, especially in case of exposure to hot water splash.

\section{Materials and Methods}

\section{Materials}

Children's sleepwear, each labelled as flame resistant, were purchased from stores and online. They were made of different fabric structures at various thicknesses using different fiber composition. They were sorted based on their fabric structure and material properties. For the sake of simplicity of the design, only 3 classes among them were selected to include in this study. Each type of samples was collected from five different garments within the same ID code. Table 1 describes the dimensional parameters of the fabrics used in this study.

Table 1: Physical properties of the fabrics.

\begin{tabular}{|c|c|c|c|c|}
\hline Fabric ID & Fiber Content & Fabric structure & Thickness (mm) & Fabric mass $\left(\mathrm{g} / \mathbf{m}^{2}\right)$ \\
\hline MI & $55 / 45$ Cotton/Modacrylic & Interlock & $0.75 \pm 0.01$ & $2.70 \pm 0.05$ \\
\hline PJ & $100 \%$ Polyester & Jersey & $0.47 \pm 0.02$ & $1.81 \pm 0.06$ \\
\hline PF & $100 \%$ Polyester & Fleece & $0.79 \pm 0.05$ & $1.72 \pm 0.03$ \\
\hline
\end{tabular}

\section{Methods}

: Fabric thickness was measured following the guidelines of ASTM D 1777-96, standard test method for thickness of Textile Materials. A Frazier Compressometer (Frazier Instrument Company, Silver Spring, Maryland) with a 2" diameter presser foot was used to measure the thickness at a pressure of 0.5 psi. Five replications were used for each measurement.

Fabric mass per unit area $\left(\mathrm{oz} / \mathrm{yd}^{2}\right)$ was determined according to ASTM D 3776-96, Option C. A precision electronic balance (MS104S, Mettler Toledo, Switzerland) was used for the measurement. An average of five measurements were reported as the value for each type of fabric.

Fiber composition was recorded from manufacturer's label.

Measurement of durability and comfort properties: Air permeability tester, abrasion resistance tester, and thermal and evaporative resistance tester were employed to evaluate the durability and comfort properties. All the samples were conditioned overnight at $21^{\circ} \mathrm{C} \pm 1^{\circ} \mathrm{C}$ temperature and $65 \pm 2 \%$ relative humidity using a conditioning chamber (LH-10 Humidity chamber, Associated Environmental Systems, Ayer, MA) before performing the tests. An average result from five specimens is reported.

Air permeability of the fabrics were tested by air permeability tester (M021A, SDL Atlas, Rock Hill, SC, USA) by following the guidelines of ASTM D737 at $125 \mathrm{~Pa}$ air pressure using $38 \mathrm{~cm}^{2}$ test head.
The abrasion resistance of the fabrics was measured by a Taber Rotary Abrasion Tester (North Tonawanda, NY, following the instruction of ASTM D 3884. Five (5) specimens of approximately $15 \mathrm{~cm}$ (6 in.) square from each sample were cut and conditioned for 24 hours in a conditioning chamber. The specimens were subjected to abrasion using $\mathrm{H}-18$ abrasive wheel and at 250 grams loading per wheel for 100 cycles. The specimen weights were determined before and after abrasion to calculate the weight loss $\%$ due to abrasion.

ASTM F1868-17 was followed to evaluate the thermal and evaporative resistance under steady-state conditions in a sweating hot plate by Thermetrics LLC (Seattle, WA, USA). Measurements were recorded for 30 minutes at $25^{\circ} \mathrm{C}$ and $65 \% \mathrm{RH}$ at an air velocity of $1 \mathrm{~m} / \mathrm{sec}$. An average of three replications was reported.

Evaluation of protection properties: Thermal protective performance properties were evaluated by vertical flammability tester, and hot liquid (scald burn) testing instrument.

ASTM Standard Method D 6545-10 (modified) was followed to determine the extent of flame spread of the children's sleepwear in a vertical cabinet from the Custom Scientific Instruments Inc. (Easton, PA, USA). Five (5) samples each of 10"x3.5" were cut from both the directions. The specimens were hung vertically in the cabinet, and exposed to a $38 \mathrm{~mm}$ (1.5 in.) flame for $3 \mathrm{~s}$. The extent of flame spread was determined by measuring the distance from the bottom of the specimen to the point where the specimen ceases to tear. The specimens were tested as received and after 50 
laundering and drying cycles. Laundering was performed following the guidelines of AATCC Test Method 124-1996 at $60^{\circ} \mathrm{C}$.

The protective performance of the children's sleepwear against hot liquid splash was evaluated following the guidelines of ASTM F2701-08 using the apparatus at Iowa State University, USA. The details on the configuration of the apparatus could be found elsewhere in the literature [18]. Briefly, the testing system consisted of a sensor board inclined at $45^{\circ}$ with the horizontal line, a water nozzle, water reservoir and a data acquisition system. The water flow was controlled by a flow control valve. A thermocouple (OMEGA: TCGG-T-30) was employed to measure the water temperature near the nozzle. Three skin simulant sensors were embedded in the sensor board at three different position of water flow. The specimens were mounted under the nozzle capable of adjusting temperature, flow, and height. Hot water at $85^{\circ} \mathrm{C}$ was sprayed on the cloth for 10 seconds, and the transmitted heat energy through the specimens was measured at three sensors positioned at different height. The $2^{\text {nd }}$ degree burn time was measured by the Stoll burn injury curve [19].

\section{Results and Discussion}

\section{Physical properties}

The physical properties of the children's sleepwear under study are presented in Table 1. Fabrics identified by PJ and PF both are made of $100 \%$ polyester fibers; whereas, MI is knitted of a blended yarn composed of $55 \%$ cotton and $45 \%$ modacrylic fiber. Table 1 shows the fabrics having different structures were made at varied thickness and mass per unit area. Fabric parameters were not controlled as they were collected from consumer market, instead they were grouped based on fiber composition, fabric weight, thickness and structure. For the simplicity of the design, only 3 classes of the collected samples coded as PJ, PF, and MI have been reported. Among them, PJ's are the thinnest, and PF's are the lightest weight fabric. On the other hand, MI's were made with high thickness and high fabric weight. The thickness of knitted fabrics is usually influenced by several factors including fabric structure, yarn diameter, loop length, and pile height [20]. PJ's and PF's had similar loop length, and mas per square meter; however, the PF's are thicker due to their pile (fleece) structure. The high thickness and weight of MI's can also be attributed to the interlock structure of the fabrics.

\section{Durability and comfort properties}

Different abrasion behavior was exhibited by different fabrics when they were subjected to 100 cycles of abrasion by using abrading wheel H-18 and 250 gm loading. The jersey structure made of polyester fibers (PJ's) exhibited the best durability properties. The weight loss \% of the PJ's was lower as compared to the MI's and PF's (Table 2). Average weight loss of the fabrics after 100 cycles were found to be $0.016 \%, 0.022 \%$, and $0.024 \%$, and for PJ's, MI's, and PF's respectively. The high weight loss of the PF's can be attributed to the pile structure, where the loose fibers at the fabric surface were easily affected by the rough abrading forces. Visual comparison of the specimens with the unabraded samples revealed that the MI's were devastated, whereas, PJ's and PF's were almost unaffected by the abrading force. This discrepancy belongs to the component fiber properties from which the fabrics were made of. Polyester fabrics (PJ's and PF's) remained unaffected from the abrasive force due to their high strength and smooth surface, but the cotton containing fabrics (MI's) were highly damaged due to the surface hairiness, and low strength of cotton fibers. The results are in good agreement with the published literature [21].

Table 2: Behavior of the fabrics against abrasion.

\begin{tabular}{|c|c|c|c|c|}
\hline \multirow{2}{*}{ Fabric ID } & \multicolumn{4}{|c|}{ Weight (gm) } \\
\cline { 2 - 5 } & Before test & After Test & \% Change & $\begin{array}{c}\text { Std. } \\
\text { Deviation }\end{array}$ \\
\hline MI & 2.97 & 2.90 & 2.22 & 2.8 \\
\hline PJ & 2.00 & 1.96 & 1.60 & 0.3 \\
\hline PF & 1.90 & 1.85 & 2.43 & 0.6 \\
\hline
\end{tabular}

Since the fabrics were made at varied thickness and mass per unit area (Table 1), they exhibited different air permeability. The average air permeability values of the fabrics MI's, PJ's and PF's were recorded as $159.20 \pm 8.61,101.33 \pm 8.50,232.20 \pm 6.10$ cubic feet per minute (cfm) respectively. Although both the PJ's and PF's were made of polyester fiber at similar loop length and mass per square meter, the jersey structure (PJ) permits less airflow than the fleece structure (PF). Loop length is the structural parameter that determine the pore size in knitted fabrics. Variation in loop length is positively related to the course spacing and wale spacing which in turn changes the pore size and porosity through which the airflow permeates [22]. The reduced airflow through the PJ's might be due to the flammable coatings applied on the fabrics that retard the airflow by blocking the pores of the structures.

The thermal comfort properties of clothing are better evaluated from the thermal resistance (Rct) and water vapor resistance (Ret), obtained from a sweating guarded hotplate or thermal manikin [23]. In fabric level, the intrinsic thermal resistance (Rcf) and intrinsic evaporative resistance (Ref), representing the heat and moisture transfer through the fabrics, are considered the two fundamental parameters of comfort. The thermal and evaporative resistances of the fabrics are exhibited in Figure 1. Correlating the results of the sweating hot plate experiment with the physical properties data from Table 1, fabric thickness appeared to be a great contributor to the Rcf and Ref values. In Figure 1, the fleece structures (PF's) exhibited both high thermal insulation, and high evaporative resistance. The high Rcf, and Ref values indicate superior thermal protection of PF's over PJ's and MI's. However, the high Rcf and Ref values of PF's are also an indicator of low heat and moisture exchange with the ambient environment. Therefore, although the fleece fabrics (PF's) provide better protective performance, they pose an absolute disadvantage of providing less comfort. On the contrary, the low Rcf and Ref values of MI's and PF's, indicate better comfort to the wearer. 


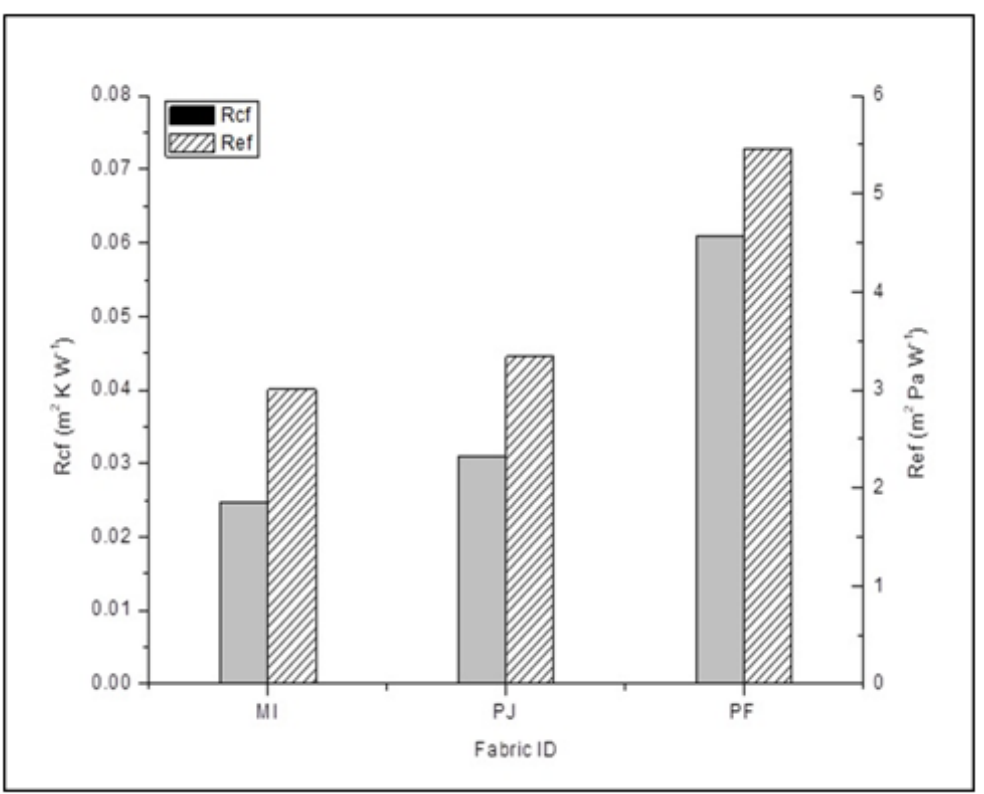

Figure 1: Thermal and evaporative resistance of the sleepwear fabrics.

\section{Protection properties}

The vertical flammability test, a recommended test as per FFA, was developed to evaluate the flammability of the children's sleepwear fabrics by exposing the fabric to fire under controlled conditions. As per the regulation (16 C.F.R. Parts 1615 \& 1616) [24], average char length of five specimens in a vertical flammability test must not exceed seven (7") inches before or after 50 washes at 60 ${ }^{\circ} \mathrm{C}$, or no individual specimen should have char length of 10 " or burning time more than 10 seconds to pass the flammability test [25]. The fabric specimens, as purchased and after 50 laundering and drying cycles, were exposed to a $38 \mathrm{~mm}$ flame for 3 seconds, and the average char lengths are tabulated in Table 3.

Table 3: Response of the fabrics under vertical flammability tester.

\begin{tabular}{|c|c|c|}
\hline \multirow{2}{*}{ Fabric ID } & \multicolumn{2}{|c|}{ Average char length (inch) } \\
\cline { 2 - 3 } & Before wash & After wash \\
\hline MI & $0.12 \pm 0.45$ & $0.12 \pm 0.45$ \\
\hline PJ & $3.12 \pm 0.42$ & $2.81 \pm 0.35$ \\
\hline PF & $3.82 \pm 1.3$ & $3.11 \pm 0.27$ \\
\hline
\end{tabular}

None of the specimens exhibited a char length of 10 inch, and average char lengths were found to be as low as 0.12 inch for MI's, and as high as 3.82 inch for PF's. Therefore, all the fabrics under study passed the recommended vertical flammability test as per FFA, and thus the hypothesis of non-conformance was nullified.

However, the burning behavior exhibited a distinctive molten polymer hazard by PJ's and PF's, as presented in Figure 2. 100\% Polyester fabrics (PJ's and PF's) didn't catch fire instantly, but once the fabric caught fire, it spread promptly, and molten polymer was drifting continuously which indicated a clear molten polymer hazard. On the contrary, The MI's, fabrics containing 55\% cotton and $45 \%$ modacrylic, was prone to catch fire due to the cotton content, but the fire didn't spread at all which could be attributed to the inherent flame-retardant nature of the modacrylic fibers. In the literature, Bourbigot et al. [10]and Kilinc FS [11] also reported the readily burning behavior of natural fibers and molten polymer hazard of the synthetic fibers. Therefore, passing the vertical flammability test is not sufficient to ensure children's protection in case of a real hazardous situation.

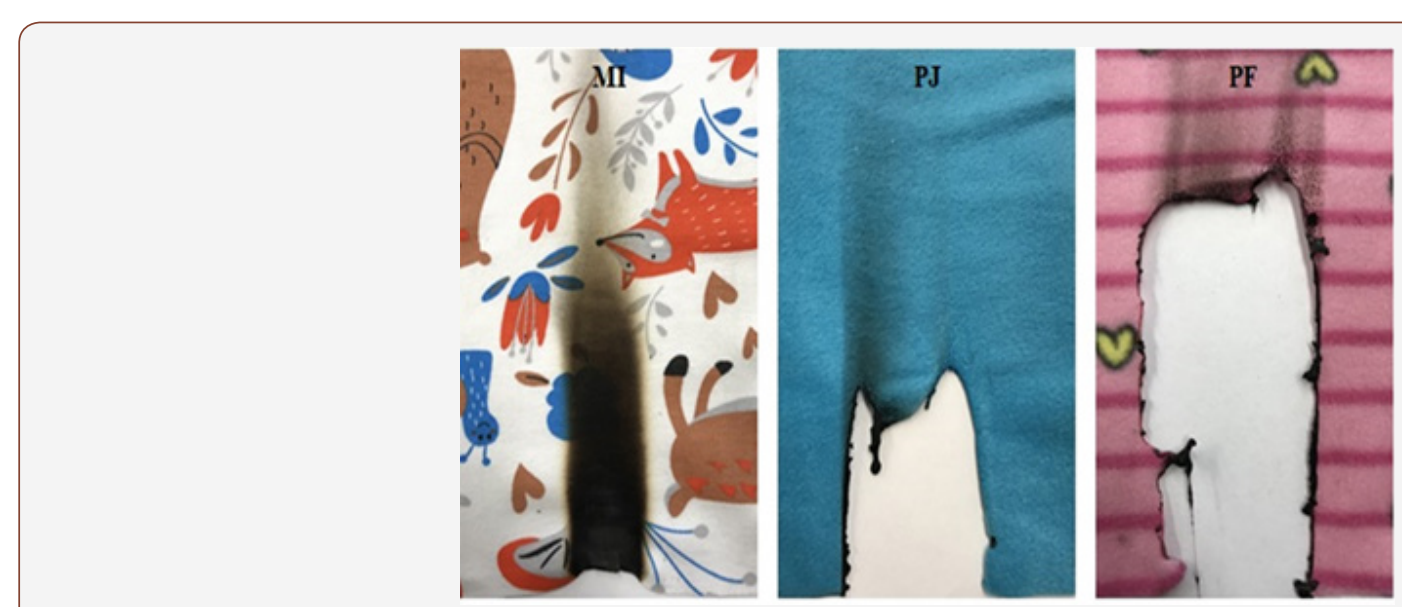

Figure 2: Fabric response to vertical flammability test (before wash). 
The scald protection was evaluated by analyzing the heat transfer through the children's sleepwear with a hot water splash of $85^{\circ} \mathrm{C}$. The surface feature upon exposure, $2^{\text {nd }}$ degree burn time, and heat flux were analyzed as predictors of fabric performance. Figure 3 provides the $2^{\text {nd }}$ degree burn time upon hot water exposure for 10 seconds at each of the three sensor positions. A burn in the place of exposure (position of top sensor) occurred as soon as 2 seconds; at a lower position (middle or bottom sensor), it took a little longer (3-5 seconds). The general trend was the increase of $2^{\text {nd }}$ degree burn time with the progressive low measurement positions. The fabrics offered poor resistance to hot liquid splash irrespective of the fiber composition or fabric structure. The polyester fleece fabrics (PF's), took the shortest time to cause a $2^{\text {nd }}$ degree burn, indicating fast spreading and penetration of the hot water through the fleece structure due to wicking of polyester fiber, and high porosity in knitted structure. It can be seen from Figure 4 that PF's store more heat energy in the structure than the other fabrics, causing a quicker $2^{\text {nd }}$ degree burn to the wearer. MI's took shorter time for $2^{\text {nd }}$ degree burn than the polyester fabrics which is due to the cotton content (55\%) in the fabric composition. Cotton, being one of the most hydrophilic fibers, absorbed the hot water instantly, and consequently heat flux reached the peak the soonest. The response to hot water splash was also studied by reducing the exposure time from ten (10) seconds to five (5), and two (2) seconds, and no remarkable changes in the results were observed.

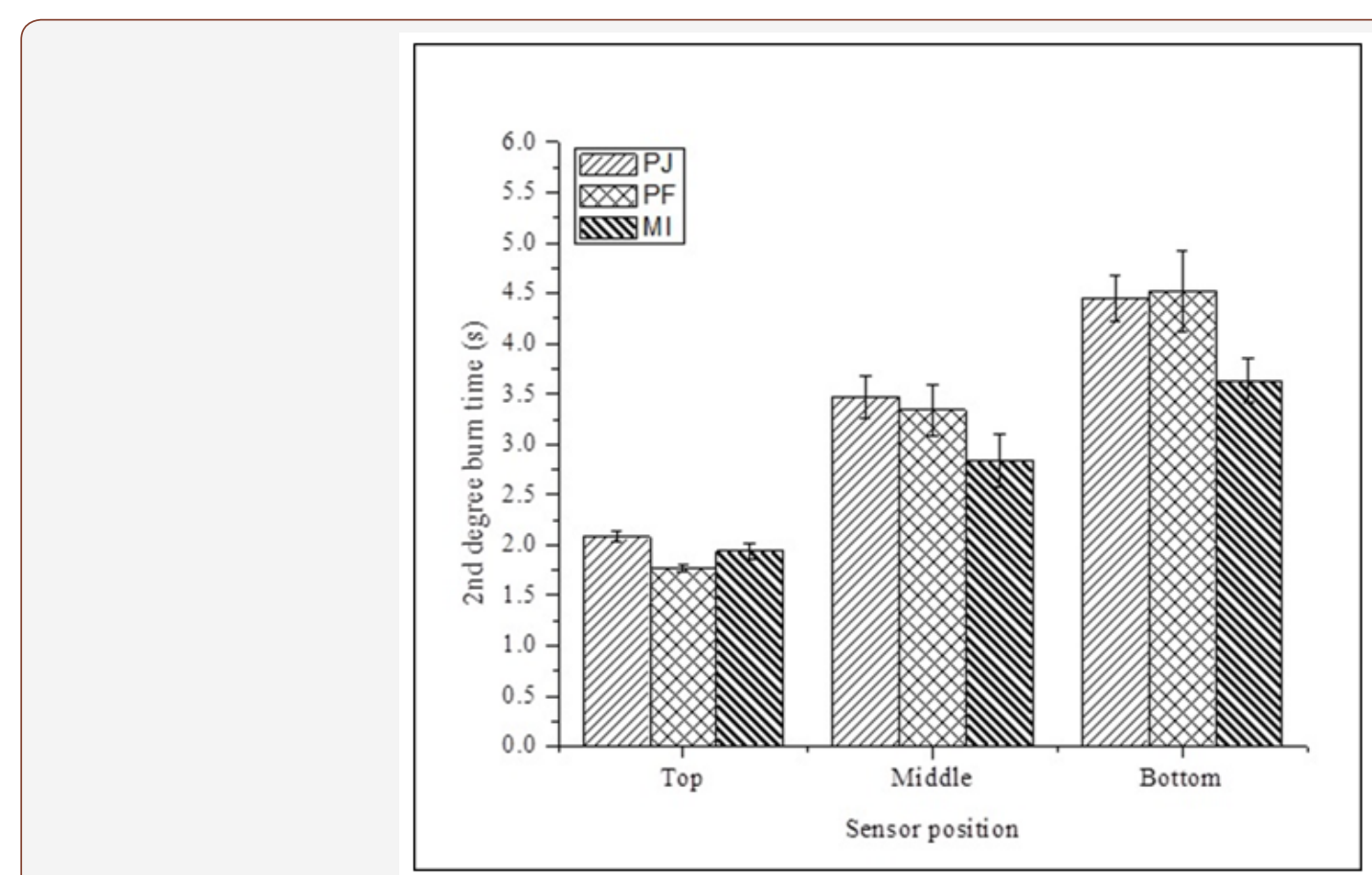

Figure 3: $2^{\text {nd }}$ degree burn time $(s)$ upon hot water $\left(85^{\circ} \mathrm{C}\right)$ splash for 10 seconds at each of the three sensor positions.

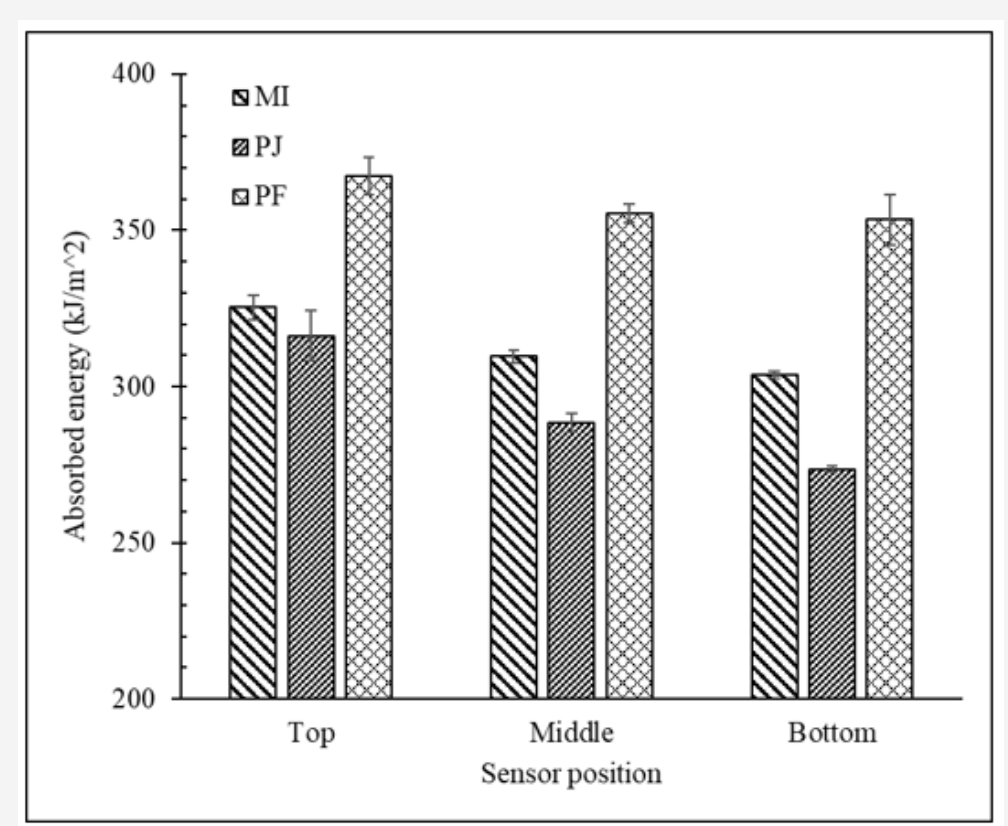

Figure 4: Absorbed energy at different sensor position. 
The hot water spread behavior (surface appearance) of these fabrics (Figure 5) provided important insight into the fabric performance. Polyester fabrics, due to better wicking property, spread hot water faster in both horizontal and vertical directions. As a result, a larger body surface area of the wearer would get burnt quickly. On the other hand, cotton/modacrylic interlock fabrics, due to excellent water absorption of cotton and high thickness of the interlock structure, would affect less body surface area, indicating superior splash protection provided.
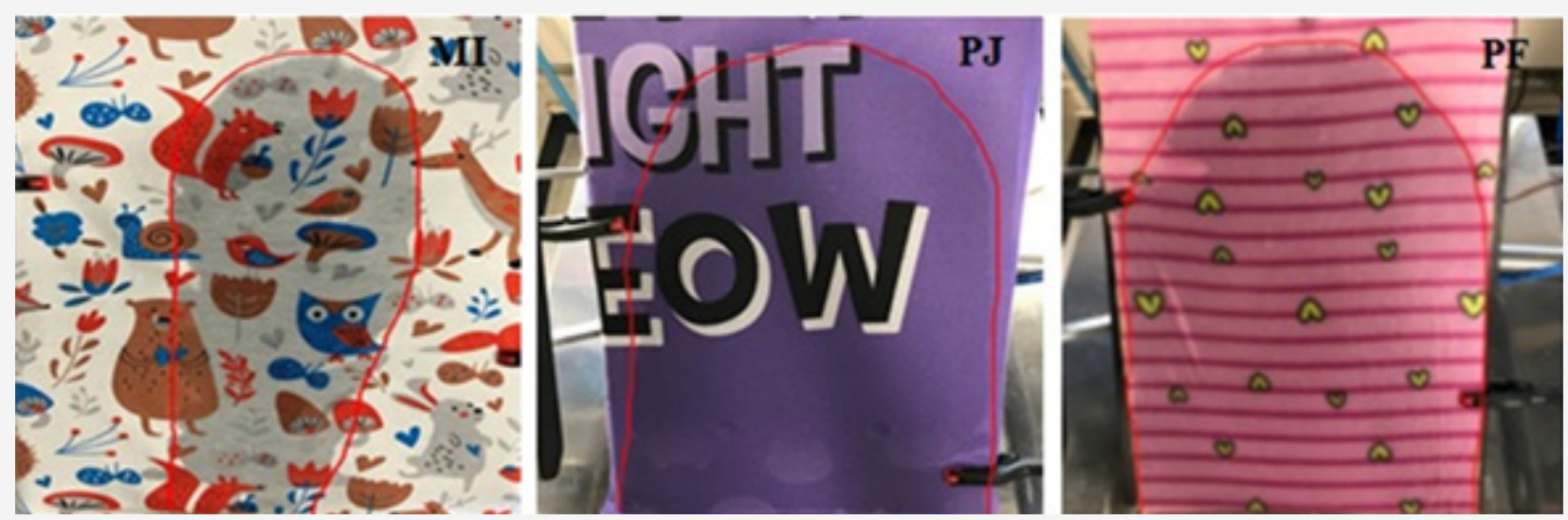

Figure 5: Surface wetting of the fabrics after hot splash.

Bearing all the test results in mind, it can be inferred that MI's, knitted from a 55/45 cotton/modacrylic blend in interlock structure, provided superior protection performance, and comfort to the wearer. A better protection could be envisioned from this fabric should they be rich in flame retardant modacrylic fiber content. The protection performance would offset the additional cost, if any, of making the fabric modacrylic rich [26].

\section{Conclusion}

The integrity of commercially available children's sleepwear in accordance with the Flammable Fabrics Act (16 CFR Parts 1615 \& 1616) of US consumer product safety commission (USCPSC) was audited. Although all the products showed good conformity with the Flammable Fabrics Act in terms of flame spread, we observed a serious issue of molten polymer hazard associated with the commonly used polyester fiber. For being the most prevalent cause of burn injury among younger children, the performance of the children's sleepwear fabrics in case of contact with hot liquid splash was also studied. Most interestingly, all the fabrics exhibited very poor protection against hot liquid; a $2^{\text {nd }}$ degree burn could be caused to the children within 2 seconds of exposure. Inherently flame-retardant fiber modacrylic containing fabric MI's in interlock structure provided the best protection. To understand a better splash protection of the children's sleepwear, broader studies including investigating the protection at various temperature of hot water, at different angle of spraying, or other liquids are required. This research would provide a critical insight into the selection of fiber and fabric structure in designing this sophisticated class of fabric for superior flame and splash protection to children.

\section{Acknowledgement}

None.

\section{Declaration of Interest}

The authors declared no conflict of interest in respect to the research, authorship and publication of this article.

\section{References}

1. Adair PK, Rodgers GB (2011) An evaluation of the impact of exemptions to the children's sleepwear flammability standards on burn injuries to children. Fire Mater 35(2): 71-81.

2. American Burn Association (2018) Burn injury fact sheet. National Burn Awareness Week Materials Chicago, USA.

3. Peck MD (2011) Epidemiology of burns throughout the world. Part I: Distribution and risk factors. Burns 37(7): 1087-1100.

4. Stanwick RS (1985) Clothing burns in Canadian children. Canadian Medical Association Journal 132(10): 1143-1149.

5. Stewart J, Benford P, Wynn P, Watson MC, Coupland C, et al. (2016) Modifiable risk factors for scald injury in children under 5 years of age: A multi-centre case-control study. Burns 42(8): 1831-1843.

6. McLoughlin E, Clarke N, Stahl K, Crawford JD (1977) One pediatric burn unit's experience with sleepwear-related injuries. Pediatrics 60(4): 405409.

7. McLoughlin E, Clarke N, Stahl K, Crawford JD (1998) One pediatric burn unit's experience with sleepwear related injuries. Inj Prev 4(4): 313.

8. Alam AKM, Wu Y, Xiang C (2018) Performance evaluation of the children's sleepwear against hot water splash. International Textile and Apparel Association (ITAA) Annual Conference Proceedings.

9. Horrocks AR, Nazare S, Kandola B (2004) The particular flammability hazards of nightwear. Fire Safety Journal 39(4): 259-276.

10. Bourbigot S, Richard-Campisi L, Le Bras M, Delobel R (1997) The thermal behaviour of a blend of cotton and fire-retardant polyester fibres: A kinetic study. J Text Inst 88(1): 64-75.

11. Kilinc FS (2013) Handbook of fire-resistant textiles. (1 $1^{\text {st }}$ edn), Woodhead Publishing Series in Textiles. Burlington: Burlington: Elsevier Science, USA.

12. Date M, Matsui H, Fukuoka S (1978) Effects of flame-retardants and the blended ratio on the flammability of polyester-cotton blended fabrics. Sen'i Gakkaishi 34(12): T569-T576.

13. Stepniczka H, Dipietro J (1971) Flammability characteristics of cotton and polyester fibers. Journal of Applied Polymer Science 15(9): 21492172.

14. (1986) The danger of polyester-cotton blends. Science News 129: 297.

15. Blum A, Ames BN (1977) Flame-retardant additives as possible cancer hazards. Science 195(4273): 17-23. 
16. Blum A, Gold MD, Ames BN, Kenyon C, Jones FR, et al. (1978). Children absorb tris-BP flame retardant from sleepwear: Urine contains the mutagenic metabolite, 2,3-dibromopropanol. Science 201(4360): 10201023.

17. Lewin M, Atlas SM, Pearce EM (1975) Flame-retardant polymeric materials. Lewin M, Atlas SM, Eli M (edts) Pearce, contributors, Plenum Press, New York, USA.

18. Lu Y, Song G, Ackerman MY, Paskaluk SA, Li J (2012) A new protocol to characterize thermal protective performance of fabrics against hot liquid splash. Experimental Thermal and Fluid Science 46: 37-45.

19. Stoll AM, Greene LC (1959) Relationship between pain and tissue damage due to thermal radiation. Journal of Applied Physiology 14(3): 373-382.

20. Majumdar A, Mukhopadhyay S, Yadav R (2010) Thermal properties of knitted fabrics made from cotton and regenerated bamboo cellulosic fibres. International Journal of Thermal Sciences 49(10): 2042-2048.

21. Akaydin M, Can Y (2010) Pilling performance and abrasion characteristics of selected basic weft knitted fabrics. Fibres Text East Eur 18(2): 51-54.
22. Bivainyte A, Mikučioniene D (2012) Influence of shrinkage on air and water vapour permeability of double-layered weft knitted fabrics. Medziagotyra 18(3): 271-274.

23. Li R, Yang J, Xiang C, Song G (2017) Assessment of thermal comfort of nanosilver-treated functional sportswear fabrics using a dynamic thermal model with human/clothing/environmental factors. Textile Research Journal 88(4): 413-425.

24. US Consumer Product Safety Commission, O of C ( $1^{\text {st }}$ edn) Children's Sleepwear Regulations, 16 CFR Parts 1615 \& 1616.

25. Nie FM, Zhu RT, Wu SH, Zhang P (2013) Review on domestic and international flammability test methods of textile. Advanced Materials Research 821: 348-351.

26. Norton MJ, Johnson RF, Jordan KA (1984) Assessment of flammability hazard and its relationship to price for women's nightgowns. Textile Research Journal 54(11), 748-760. 